Research Journal of Applied Sciences 13 (6): 387-398, 2018

ISSN: $1815-932 \mathrm{X}$

(C) Medwell Journals, 2018

\title{
Inequality Asses of Emergency Medical Services Since Urban Accessibility Measures
}

\author{
${ }^{1}$ Juan Manuel Holguin, ${ }^{2}$ Diego Alexander Escobar and ${ }^{3}$ Daniel Ricardo Oviedo \\ ${ }^{1}$ Universidad Nacional de Colombia, Circular 4\#70-93 Int. 403, 050031 Medellin, Colombia \\ ${ }^{2}$ Universidad Nacional de Colombia, Cra 27\#64-60 Off.I-408, \\ 170004 Manizales, Colombia \\ ${ }^{3}$ University College London, Gower Street, London WC1E 6BT, United Kingdom
}

\begin{abstract}
In recent decades, identification of social inequalities in transport has claimed a new found relevance in academic circles. Special attention has been given to the social consequences of unequal access to different urban services and amenities. The city of Manizales, Colombia is one example of a spatially and socio-demographically segregated city in the global South. Such segregation has visible effects among different social groups on the levels of access to essential services for their well-being such as healthcare. This research examines inequalities in access to emergency service facilities between different social groups from a spatial perspective in urban areas. Using geographic information system and socio-demographic and economic secondary data as well as primary information from emergency service providers in the city, we identify levels of geographic accessibility to emergency service facilities in areas with marked differences in terms of income, access to infrastructure and local availability of healthcare facilities throughout Manizales. Our findings reflect wide gaps in the time required to respond to a medical emergency in areas of different socio-economic strata in the city.
\end{abstract}

Key words: Accessibility, emergency service facility, social inequality, spatial inequality, ambulance dispatch, infrastructure

\section{INTRODUCTION}

Health inequality studies have mainly focused on measuring quality of services, financial affordability and information availability (Pickett and Wilkinson, 2015). 'Most of the research to date has focused on equality of treatment and/or health outcome rather than on equality of opportunity' (Neutens, 2015). Furthermore, social inequality regarding access to transport and opportunities has recently gained relevance in academic and policy circles. The analysis of accessibility can help to identify in great detail how different urban areas can suffer from lower levels of accessibility including healthcare (Higgs, 2004). In the global South, low life expectancy, high rate of road traffic accidents, absence of services or amenities and low human resources are some examples of health issues that burden the system in low and middle income countries. However, these are a product of social inequalities due to differences in the distribution of income, education, etc.
The term mobilities describes the displacement of people, goods and information (Ohnmacht et al., 2009) the location of medical emergencies is framed by ease of access to ESFs, quality and density of transport infrastructure are factors that impact efficient mobility. Thus, a lack of access to resources is a contributor to mobility inequalities (Ohnmacht et al., 2009; Sheller and Urry, 2006). Accessibility is one way to assess the impacts of land use and transport strategies such as defining the most efficient location for healthcare services according to different factors such as access time, technological and human resources, etc. (Geurs and Wee, 2004; Higgs, 2009). In a number of studies, accessibility methodologies have facilitated better planning and coverage of healthcare facilities. For instance in Mississauga, Canada, access to healthcare has important disparities due to some patients looking for physicians with certain language capabilities (mother tongue) (Bissonnette et al., 2012). In Niger, areas were identified that lacked healthcare facilities and overestimated demand

Corresponding Author: Juan Manuel Holguin, Universidad Nacional de Colombia, Circular 4\#70-93 Int. 403, 050031 Medellin, Colombia 
because measurements were only taken during the dry season and significant changes occur in the wet season (Blanford et al., 2012). In Rwanda, the accessibility to healthcare facilities was assessed through three travel scenarios (walking, walking and cycling, walking and public transport), finding that walking and cycling were the best options to ensure the highest coverage of the population (Munoz and Kallestal, 2012).

Inaccessibility is related to the lack of amenities and transport (Church et al., 2000; Graham and Marvin, 2001). In cities in the global South, there are greater transport disadvantages and social exclusion in the peripheral zones where low income groups coexist (Lucas, 2011; Hernandez and Titheridge, 2016) with black or coloured people who live long distances from their jobs or education. These areas also have insufficient services and amenities including clinics, hospitals and libraries (Lucas, 2011). Moreover, emergency medical transportation used in the global north is expensive for countries in the global South (Razzak and Kellermann, 2002). The health inequalities induced by health system in every country could be overcome providing access to everyone, adequate resources and function properly (Marmot, 2007). Some researchers have sought to discover the best choices for healthcare planning in broad areas such as a country (McGrail and Humphreys, 2014). However, the inequality in access to these amenities has rarely been studied (Hawthorne and Kwan, 2012). Planning of healthcare services is not focused on overcoming social inequalities but rather geared towards profitability.

Evaluating accessibility to Emergency medical Services (ESF and $\mathrm{AD}$ ) must consider minimum travel time which is the principal factor that decreases mortality rates (Cromley and McLafferty, 2011). Researchers have been focused on correlating the response time (interval between the $\mathrm{AD}$ and arriving on the scene) with deaths. For instance, one study found an interval of $5 \mathrm{~min}$ was related with enhanced survival in urban areas (Blackwell and Kaufman, 2002). Other researchers for non-traumatic cardiac arrest patients, found an interval between 0 and 4 min of response time (interval between $\mathrm{AD}$ and event) to have more probabilities to still alive (Pons et al., 2005). Many researchers are making efforts to improve services in the future in terms of planning and response time (Indriasari et al., 2010; Sasaki et al., 2010). However, there are several factors that are difficult to take into account, including scene time, time of call, traffic jams, Emergency medical Services (ESF and AD) being far away, etc.

ESF are one of many healthcare services and are usually located in a hospital or other primary care centre. These facilities provide medical care for critical and non-critical patients who are transported by ambulance. However, in a life-threatening emergency, patients face many critical factors including time (Blackwell and Kaufman, 2002). These factors become even more critical in low and middle income countries as access to ESF is unequal. For instance, in Monterrey, Mexico, the death rate inside ambulances decreased from 8.2-4.7\% when $\mathrm{AD}$ was increased from two facilities to four between 1992 and 1997 (Arreola-Risa et al., 2000) demonstrating the importance of rapid response. However, there are some countries where ambulances are not the best option to arrive at an ESF. In Tanzania, bicycles with trailers, tricycles with platforms and tractors with trailers are used for emergency transportation (Schmid et al., 2001).

The research hypothesis is based on the fact that exists inequality in the provision of emergency services which is intensified by poor urban planning and the geographical patterns of recorded emergencies. Hence, this research seeks to link social and health inequalities in access to Emergency Service Facilities (ESF) and Ambulance Dispatches (AD) through an analysis of spatial accessibility and the coverage of emergencies that occurred between 2010 and 2015, comparing Life-Threatening (LT) and Non-Life-Threatening (NLT) emergencies. We chose Manizales, Colombia, capital of the province of Caldas in Central Colombia (Fig. 1) which has special characteristics such as abrupt topography and a lack of urban planning with its historic development along the hills. Manizales has been marked by limited land-use regulations that have led to the development of informal settlements in unsuitable land and environmentally risky areas (Chardon, 2008).

The government has tried to relocate some of these informal neighbourhoods to the peripheral areas which contributes to socio-spatial segregation of the city. A proxy for such socio-spatial segregation is reflected in the socio-economic strata. Because every residential estate that uses public utilities is categorized in a stratum according to the economic capacity where stratum 1 is generally associated with low-income populations and stratum 6 with the richest citizens. This research explores how gaps between social groups and urban spatial distribution of facilities and population reveal some inequalities. Manizales has 404, 805 inhabitants, population growth is $<1 \%$ per year; also, the number of elder citizens is increasing roughly $1-3 \%$ per year, intensifying the pressure on the healthcare system. 

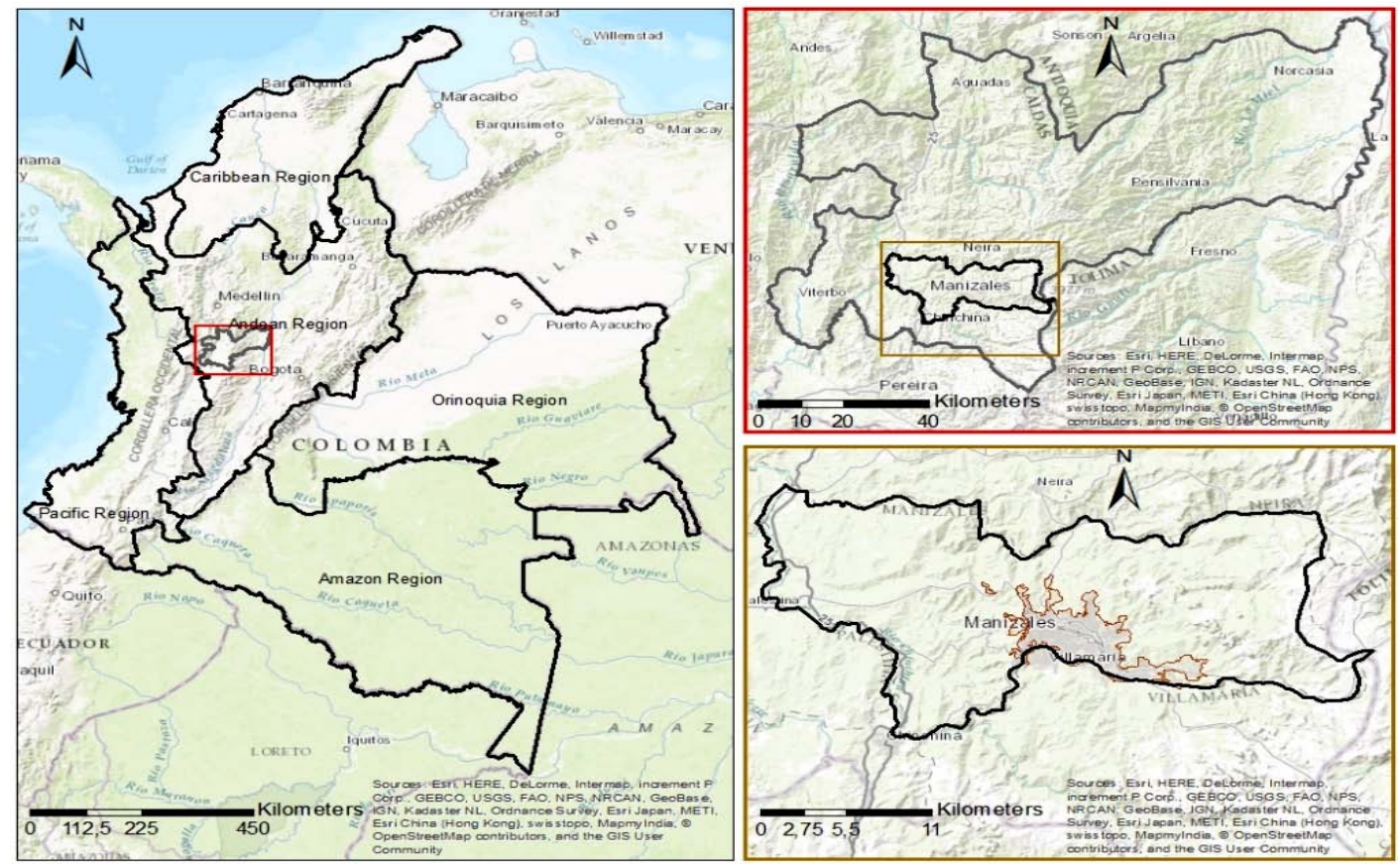

Fig. 1: Location of Manizales researcher from ESRI

\section{MATERIAL AND METHODS}

The combination of statistical, GIS and road infrastructure datasets defined the model for analysis. The performance of the applied methods depends on data variation, finding that as the variation increases, the accuracy of all methods decreases and the magnitude of decrease is method dependent ( $\mathrm{Li}$ and Heap, 2011). The methodology have five stages and is described as follows.

Analysis of emergency database: Data for emergency events include 19 variables such as date, name of ambulance, type of illness, location of event and name of ESF where patient was attended. However, this data was a mess due to writing and standardisation of variables. Hence, it had a process of cleaning and transforming to define the usable data. A total of 12,810 events were georeferenced between 2010 and 2015 (excluding 2012) with an average of 2,562 events per semester and a standard deviation of 133 events per semester. Triage of each event was specified by a physician, reducing usable data to 11,024 events of which 10,594 events were emergencies. In the research were used emergency data from the fire brigade of Manizales. The emergency events were georeferenced in order to link the database generated with the spatial location of each event and the $\mathrm{ESF}$ and $\mathrm{AD}$ location.
Review and updating of the road network and georeferencing Emergency Services Facilities (ESF) and Ambulance Dispatches (AD): In this research, the road network is a digital node-and-link database represented by a graph composed of 12,626 links and 8,837 nodes, located geospatially. It was used the latest available information for the Anonymous (2011) which were updated using data collected by GPS equipment. The healthcare system in Colombia researches through EPS and IPS (Health Insurance Companies and Health Facilities, respectively acronyms in Spanish) in Manizales, there are about 142 IPS. However, 14 entities could attend Emergencies (ESF) which were georeferenced as points on the model through direct observation. The ambulances that attend emergencies in Manizales belong to the government through civil defence (Special group prepared for non-combatant assistance to individuals such as rescue, firefighting, first aid, shelter, feeding, etc.), fire brigade and GER (Special Group of Rescue; acronym in Spanish) and to the NGO's through Red Cross, BYR (Search and Rescue; acronym in Spanish) in six locations of the city, two of them belonging to the fire brigade.

Calculation of operative characteristics of the available road network: The road network dataset has an average passenger-car speed by link and is a crucial input in geographical accessibility analysis (Geurs, 2001) which was used to determine travel time by link which was 
applied to calculate the shortest paths for $\mathrm{AD}$ and ESF, using the algorithm by Dijkstra. It is used a spatial approach to analyse accessibility of $\mathrm{AD}$ to emergency events and from emergency events to ESF, based on the shortest travel time (Cromley and McLafferty, 2011).

Calculation of average mean accessibility: The minimum travel time of each node or emergency is calculated in order to obtain the average travel time vector. Travel time vector is shown as isochronous curves which were calculated using a geostatistical interpolation methods (Li and Heap, 2011). Every sampled node has a weight $(\lambda)$. It depends of the distance between the zone that will be predicted and the sample nodes. For short distances, would have more weight than great distances. The travel time of the points was multiplied by each weight, forecasting travel times in the entire area being studied using the following functions in Eq. 1 and 2:

$$
\begin{gathered}
\mathrm{T}_{\mathrm{vi}}^{*}\left(\mathrm{X}_{0}\right)=\lambda_{1} \mathrm{~T}_{\mathrm{vi}}\left(\mathrm{X}_{1}\right)+\lambda_{2} \mathrm{~T}_{\mathrm{vi}}\left(\mathrm{X}_{2}\right)+\lambda_{3} \mathrm{~T}_{\mathrm{vi}}\left(\mathrm{X}_{3}\right)+ \\
\lambda_{4} \mathrm{~T}_{\mathrm{vi}}\left(\mathrm{X}_{4}\right)+, \ldots,+\lambda_{\mathrm{n}} \mathrm{T}_{\mathrm{vi}}\left(\mathrm{X}_{\mathrm{n}}\right) \\
\mathrm{T}_{\mathrm{vi}}^{*}\left(\mathrm{X}_{0}\right)=\sum_{\mathrm{i}=0}^{\mathrm{N}} \lambda_{\mathrm{i}} \mathrm{T}_{\mathrm{vi}}\left(\mathrm{X}_{\mathrm{i}}\right)
\end{gathered}
$$

This methodology was based on kriging method; the first develop of this method was carried out by Matheron (1963), based on the Master's thesis by Krige, a South African Mining Engineer who used this technique to predict mineral reserves. Currently, Kriging method has become an important geostatistics tool and it is used in many topic areas. Geostatistical methods for spatial interpolation are used to forecast count values at unmeasured locations while computing the errors of these predictions. They are based on the principle that unobserved variables are autocorrelated over space and this autocorrelation level decline with distance. Besides, the values for forecasting depend on several observable causal factors (e.g., physical characteristics of road network and facility type). In general, spatial variables could be defined as showed in Eq. 3:

$$
Z_{i}(s)=\mu(s)+\varepsilon_{i}(s)
$$

Where:

$$
\begin{aligned}
& Z_{\mathrm{i}}(\mathrm{s})=\text { The average travel time, variable of interest } \\
& \mathrm{s}=\text { The location coordinates }(\mathrm{x}, \mathrm{y}) \text { of site } \mathrm{i} \\
& \mathrm{Z}_{\mathrm{i}}(\mathrm{s})=\text { The sum of the deterministic trend } \\
& \mathrm{s}=\text { An explanatory function of variables at location } \\
& \quad \mathrm{i} \text { and a spatially dependent error term } \\
& \varepsilon_{\mathrm{i}}(\mathrm{s})=\text { Generally, the errors are correlated over space }
\end{aligned}
$$

The level of dataset spatial autocorrelation rely on three semivariogram's parameters: nugget effect, range and sill (Wang and Kockelman, 2009). So, in this research, the universal kriging method predicted the average travel time for locations where there were no nodes in the network, to build isochronous curves of minimum travel time. Then, this method is a spatial estimation where the error variance is minimized and was estimated unknown values from the known values.

Analysis of coverage of isochrones curves: Isochronous curves were intersected with emergencies and socioeconomic zones per year. Assessing coverage of emergencies with minimum travel time (event was attended by the nearest $\mathrm{AD}$ and by the nearest ESF) and measuring the coverage of emergencies, finding the time between the actual $\mathrm{AD}$ that was dispatched to the event and between the event and actual ESF that attended the emergency, according to the stratum (where stratum 1 is households with low economic capacity and stratum 6 are households with high economic capacity) of the event location and accounting for the nature of the event (i.e., LT or NLT). This made it possible to calculate the percentages of the population (404,805 inhabitants), number of households $(95,361)$ and area $\left(39.3 \mathrm{~km}^{2}\right)$ that are covered by the different isochrones curves.

Then, we estimated the loss of time for patients with $\mathrm{LT}$ due to two factors. First, $\mathrm{AD}$ did not leave from the nearest place. Second, the patient was not transported to the nearest ESF. We quantified the events with loss of time and optimal time by stratum of the event location per year. Also, we measured the loss of time by stratum per year. Finally, this study evaluated the spatial accessibility for deaths from $\mathrm{AD}$ and to ESF. In this step, the socioeconomic zones were intersected with deaths and isochrones curves per year. We calculated the coverage of deaths and loss of time by stratum per year. Loss of time was calculated, firstly through a matrix with shortest travel time between each $\mathrm{AD}$ to each emergency. Secondly, another matrix was created with shortest travel time amongst each emergency to each ESF. Thirdly, in each matrix, we subtracted actual travel time from minimum travel time.

\section{RESULTS AND DISCUSSION}

According to isochronous curves both from $\mathrm{AD}$ and to ESF (Fig. 2 and 3), peripheral zones were outside of the optimal response time and transport time (zones were attended by the closest $\mathrm{AD}$ and $\mathrm{ESF}$, respectively) but $\mathrm{ESF}$ had more coverage than $\mathrm{AD}$. Knowing that 


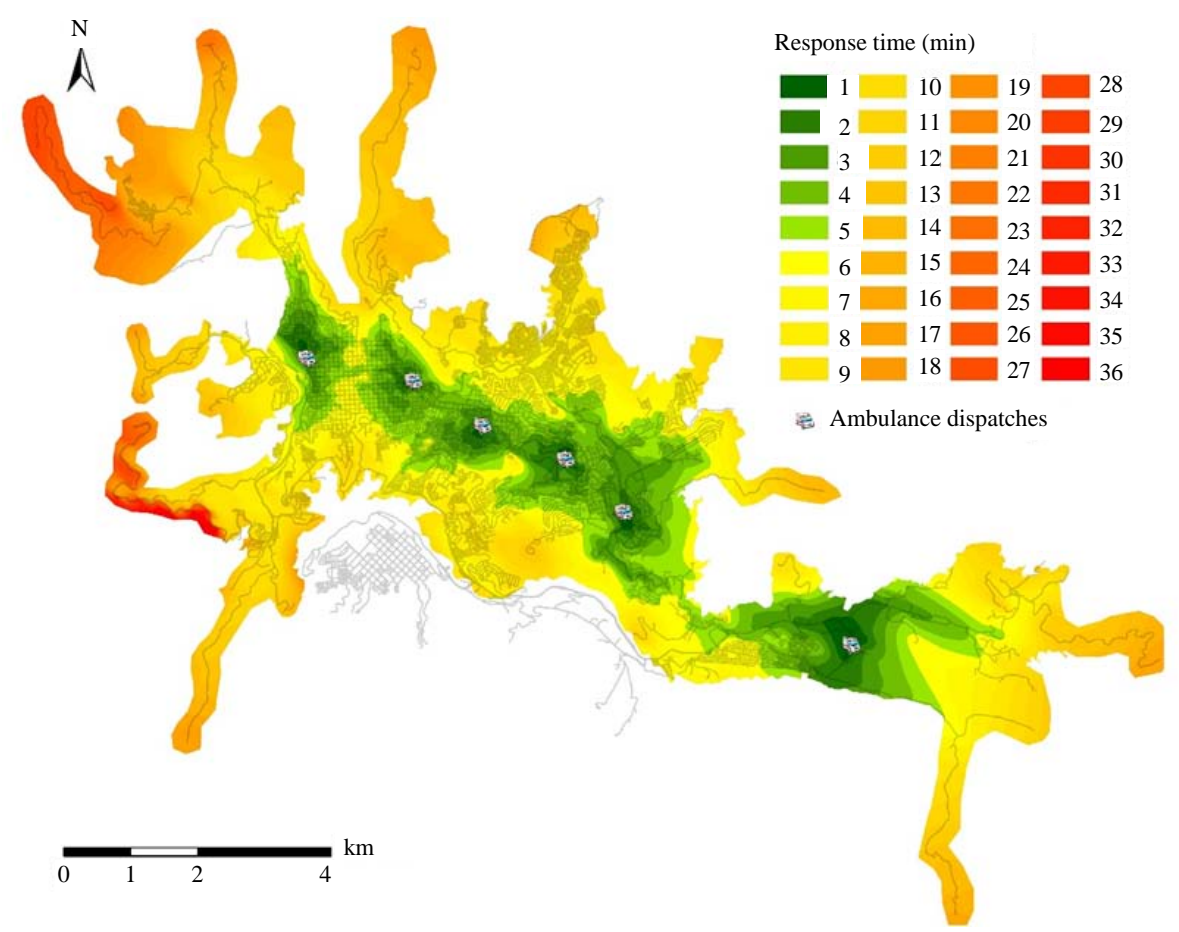

Fig. 2: Spatial accessibility from $A D$ in urban area of Manizales researcher

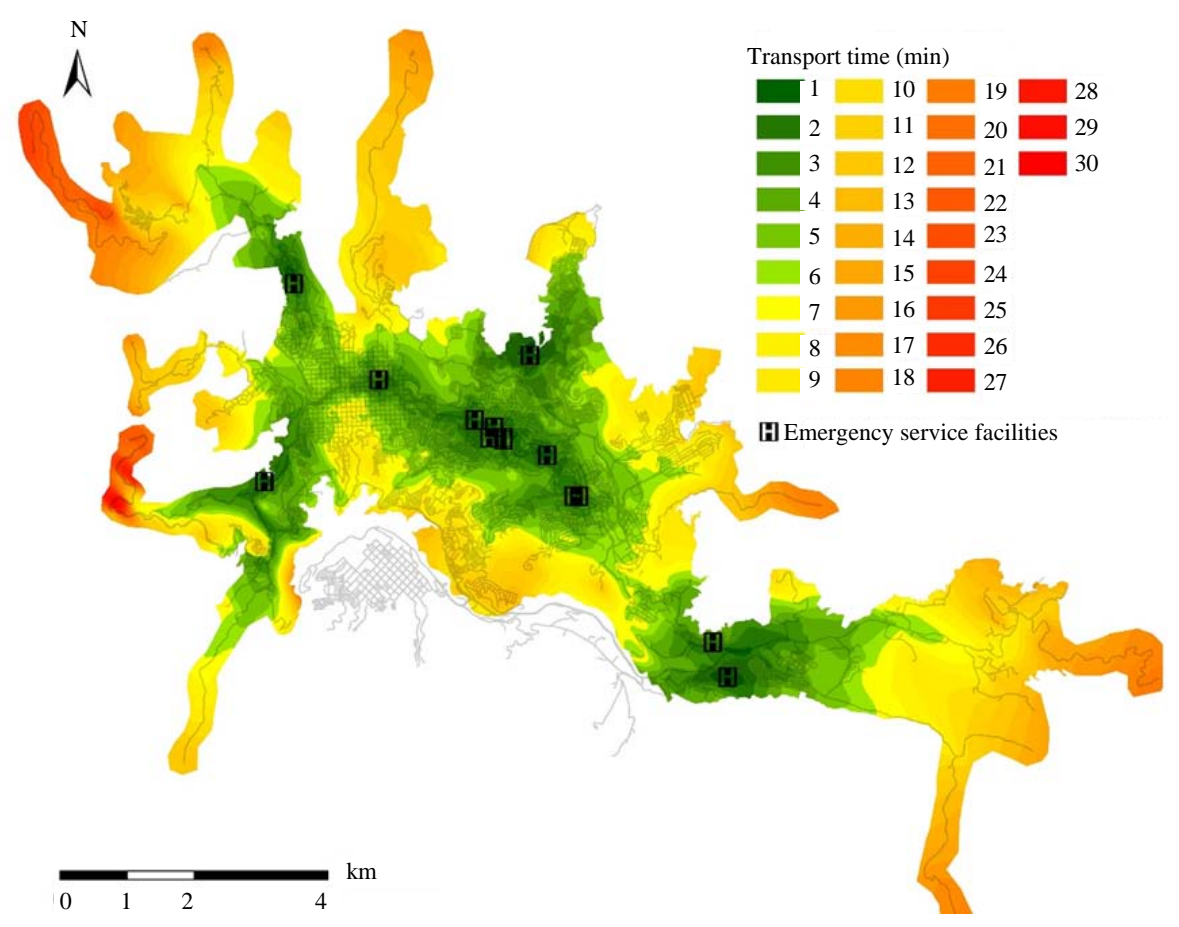

Fig. 3: Spatial accessibility to ESF in urban area of Manizales researcher

low income people live in these locations, these residences suffer a lack of $\mathrm{AD}, \mathrm{ESF}$ and road infrastructure caused by high slope and dreadful urban planning.
Coverage of emergencies by nearest AD (optimal): In 2015 if LT emergencies had been attended by the nearest $\mathrm{AD}$, the coverage by stratum are shown in Fig. $4 \mathrm{a}$ and for NLT emergencies in Fig. 4b. The events which occurred 


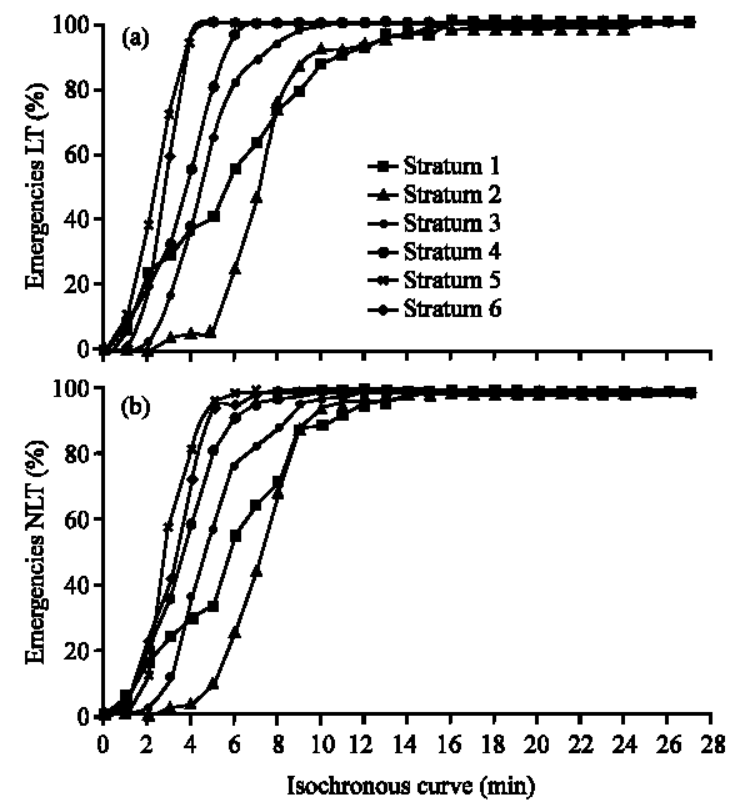

Fig. 4: Covered percentage per type of emergency by stratum with minimum response time from $\mathrm{AD}$ in 2015 ; a) Life-threatening events and b) Non-life-threatening events researchers

in stratum 1 and 2 zones had the worst accessibility. For LT events, $7 \%$ of emergencies in stratum 2 zones had $5 \mathrm{~min}$ of travel time. In contrast, for LT events in stratum 5 and 6 zones, close to $100 \%$ had $5 \mathrm{~min}$ of travel time.

This highlights the social inequalities in access to $\mathrm{AD}$. For NLT emergencies, high income zones had $100 \%$ coverage while events in stratum 2 had coverage of $11 \%$. Additionally, there was no difference in LT events and NLT events. Next, we compared the cumulative percentages of LT events in stratum 2 zones with 5 min of response time per year. In 2010, 2011, 2013, 2014 and 2015 the coverages were $15,11,1,16$ and $7 \%$ respectively. Between the years, there was not a huge difference, although, 2015 showed the minimum coverage. Even though social inequalities and health inequalities have been growing, the coverage could be considered relatively constant. According to $\mathrm{NLT}$ events in stratum 2 , the coverages with $5 \mathrm{~min}$ of travel time were: $18 \%$ in $2010,11 \%$ in $2011,14 \%$ in $2013,9 \%$ in 2014 and $11 \%$ in 2015. This means that coverage was very continuous and the attention to LT and NLT events was similar but the percentages were very low. These sectors need better infrastructure and $\mathrm{AD}$ to improve the service and overcome social gaps which should be public policy (Anonymous, 2016a, b).

Coverage of emergencies by registered AD (Actual): Emergencies were not always attended by the nearest
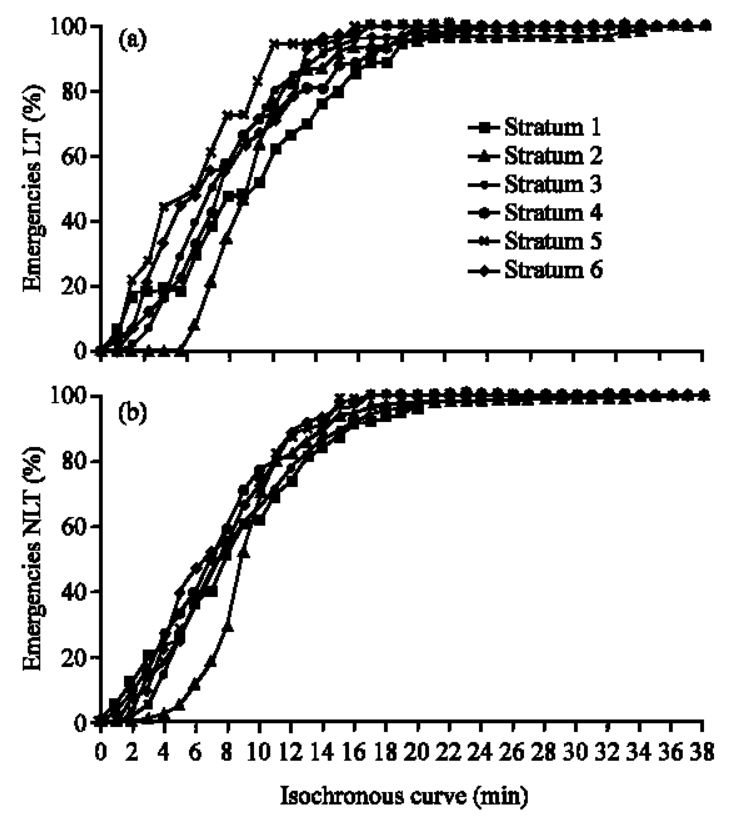

Fig. 5: Covered percentage per type of emergency by stratum with actual response time from $\mathrm{AD}$ in 2015; a) Life-threatening events and b) Non-life-threatening events researchers

$\mathrm{AD}$; the coverages changed significantly (Fig. 5a, b) for both LT and NLT events when attended by the $\mathrm{AD}$ that actually dispatched the ambulance. For instance, $0 \%$ of LT emergencies in stratum 2 were covered in $5 \mathrm{~min}$, whilst $44 \%$ of LT events in stratum 5 were covered in $5 \mathrm{~min}$. For NLT emergencies in stratum $2.6 \%$ were covered in $5 \mathrm{~min}$ while NLT events in stratum $5.44 \%$ were covered in $5 \mathrm{~min}$ the same as LT urgencies. Although, all coverages were less than coverages obtained by the nearest $\mathrm{AD}$, social and health inequalities are still present. When the delta between strata was less, this was usually due to a failure in logistics, not an attempt to overcome social gaps.

In a comparison of coverages by years for $\mathrm{LT}$ events in stratum 2 with 5 min of travel time between $\mathrm{AD}$ that actually attended the event, 2013 had the highest coverage with $14 \%, 2010$ was $9 \%, 2011$ was $11 \%, 2014$ was $9 \%$ and 2015 was $0 \%$. Given that the first 4 years had similar percentages but the last year was 0 indicates the lack of planning in logistics and territory. Similarly, for NLT events, the highest coverage was in 2010 with $10 \%$, the next 3 years of study had 3\% of coverage and 2015 was $6 \%$. Although, both coverages of LT and NLT events with $5 \mathrm{~min}$ of travel time were considerably low, this shows a priority of attention to LT events. Nevertheless, these percentages do not enable definitively concluding this. 

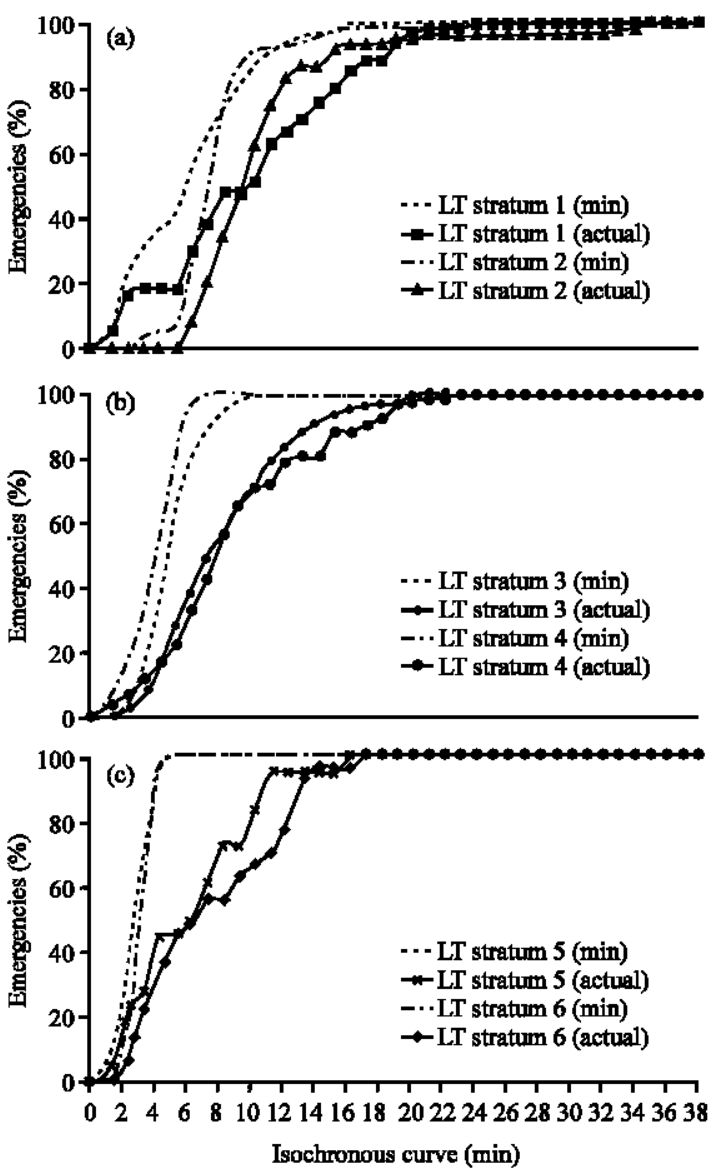

Fig. 6: Comparison of coverages between minimum response time and actual response time of $\mathrm{LT}$ emergencies by $\mathrm{AD}$ and by stratum; a) 1 and 2 ; $\mathrm{b}$ ) 3 and 4 and c) 5 and 6 researchers

Comparison of coverages between minimum travel time and actual travel time of LT emergencies by $\mathrm{AD}$ : Comparing coverage with minimum travel time (Nearest AD-Emergency) and coverage with actual travel time (Actual $\mathrm{AD}$ which attended event-emergency), the highest time gap was in stratum 5 and 6 (Fig. 6a-c). In intervals of $5 \mathrm{~min}$ for 2015 , there was a difference of $56 \%$ of coverage in emergencies in stratum 5. For stratum 2 , the maximum gap was $8 \mathrm{~min}$ with a difference of $40 \%$.

In a comparison of the time gaps between years with an interval of $5 \mathrm{~min}$ for events in stratum 5 , in 2010 there was a difference of $72 \%$, in 2011 of $75 \%$, in 2013 of $65 \%$, in 2014 of $50 \%$ and in 2015 of $56 \%$. With an interval of $8 \mathrm{~min}$ which was the most common maximum time gap in coverage of emergencies in stratum 2 , in 2010 there was a difference of $27,37 \%$ in $2011,36 \%$ in $2013,38 \%$ in 2014 and $40 \%$ in 2015 . Time gaps have been decreasing for high income zones while for low income zones, they have been increasing. More social inequalities arise due to first

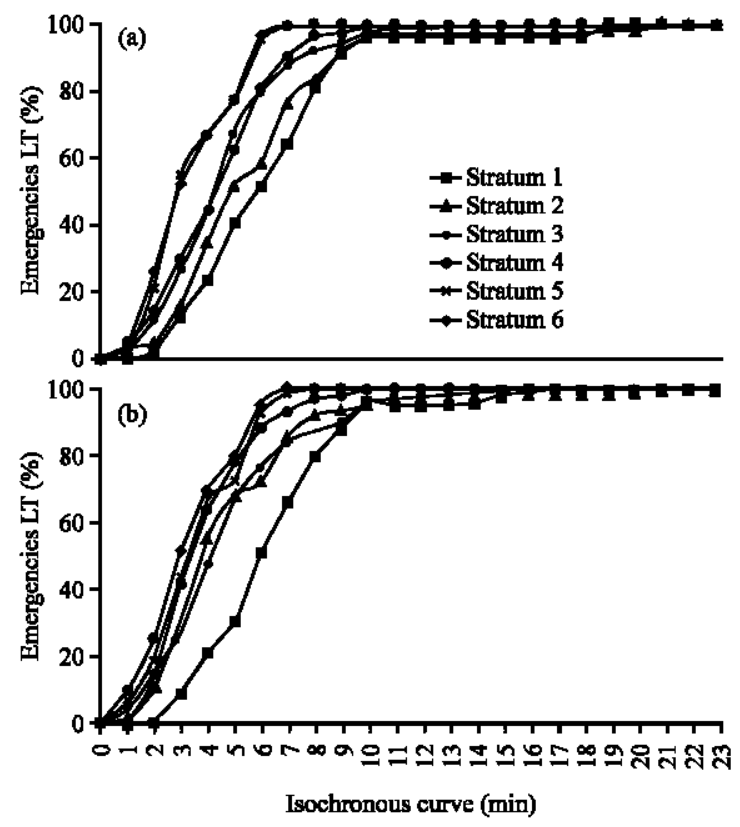

Fig. 7: Covered percentage per type of emergency by stratum with minimum transport time to ESF in 2015; a) Life-threatening events and b) Non-life-threatening events researchers

a lack of access and second a failure in logistics as seen in data from recent years in stratum 1 and 2 . Conversely, the highest time gaps were in high income zones due to there being more $\mathrm{AD}$ than other zones. Hence, when an emergency occurs in stratum 5 or 6 and is not attended by the nearest $\mathrm{AD}$, this generates huge gaps. When an emergency happens in stratum 1 or 2 and is not attended by the nearest $\mathrm{AD}$, it does not produce a large difference in time because the time gap between the nearest $\mathrm{AD}$ and the $\mathrm{AD}$ which actually attended the event was not significant as they are both far away.

Coverage of emergencies by nearest ESF (optimal): Considering that emergencies are attended by the nearest ESF, the coverage shown in Fig. 7a, b reveals the lowest coverage with an interval of $6 \mathrm{~min}$ for both LT and NLT events in stratum 1: 52 and $51 \%$, respectively. For LT and NLT events in stratum 5 with the same interval of time, there would have been a coverage of 94 and $92 \%$, respectively. Similar to the coverage for the nearest $\mathrm{AD}$, social inequalities are present for ESF.

However, the coverages of emergencies in stratum 2 were better due to one ESF located in the North of Manizales in a neighbourhood in this stratum. However, this means that all the actors (government, private sector, ONG, etc.) must make efforts to improve emergency medical services. In the 5 years being studied, the tendency of coverages for LT and NLT events stratum 1 


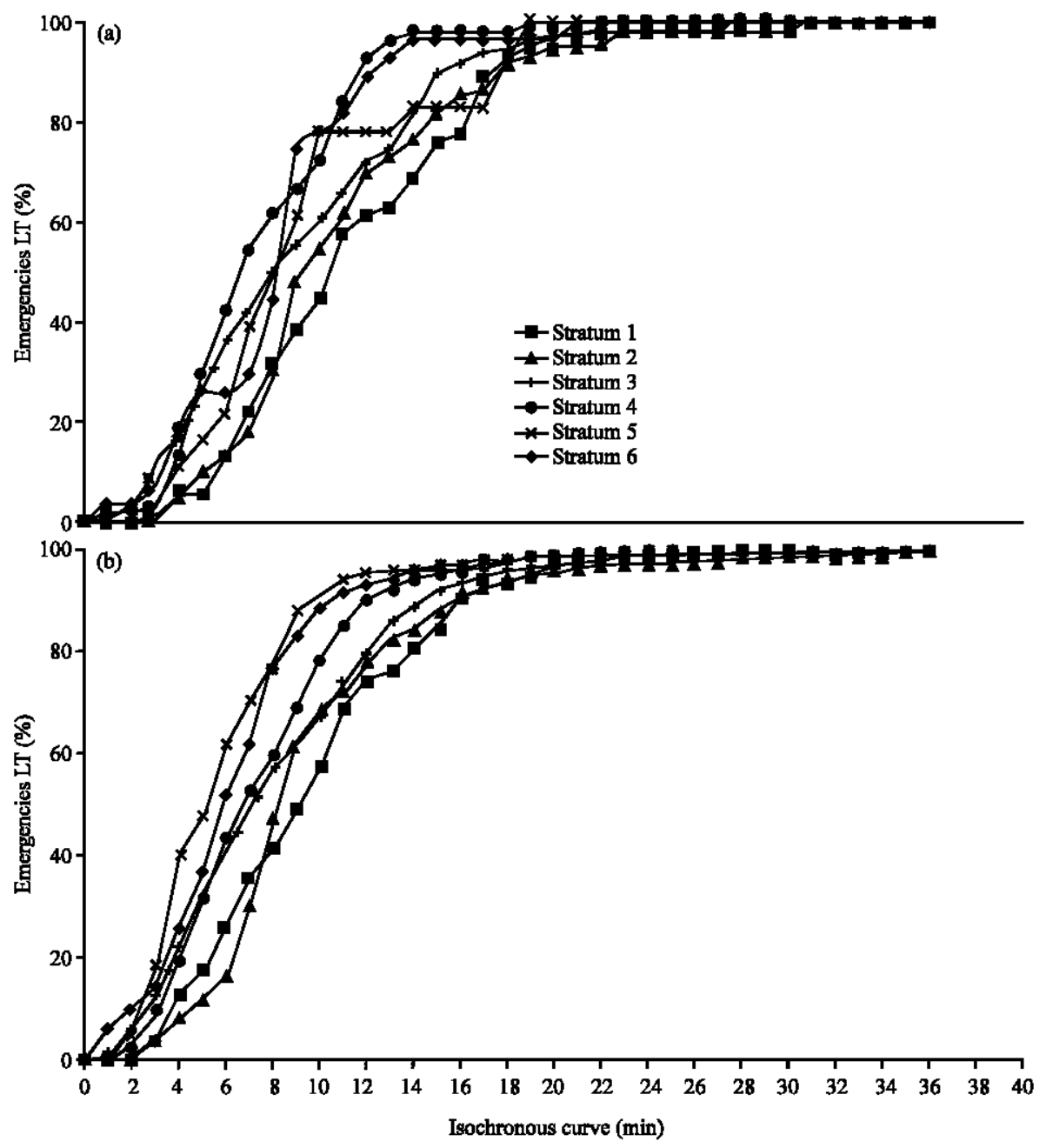

Fig. 8: Covered percentage per type of emergency by stratum with actual transport time to ESF in 2015; a) Life-threatening events and b) Non-life-threatening events researchers

with 6 min of travel time was similar where for LT emergencies the coverage was $40 \%$ in $2010,20 \%$ in 2011 , $32 \%$ in $2013,49 \%$ in 2014 and in 2015 was $52 \%$. NLT events coverage in 2010, 2011, 2013, 2014 and 2015 was 39, $53,53,49$ and $51 \%$, respectively. For LT emergencies in stratum 5 , the coverages in each year were $94,100,100$, 100 and $94 \%$ respectively. For NLT events in stratum 5, coverages were $100,93,98,91$ and $92 \%$, respectively. This indicates that for low income zones there was a priority of NLT emergencies in the journey to ESF in the first 3 years of study while for high income sectors there was a priority of LT events in the 5 years of study.

Coverage of emergencies by registered ESF (actual): Coverage of LT and NLT emergencies by ESF which actually attended the event were different from coverage with nearest ESF (Fig. 8a, b). In this case, the coverage for both types of events in all strata were similar. However, the low income zones had the worst coverage and accessibility. For instance, 6 minutes of transport time coverage for LT emergencies in strata 1 and 2 was $13 \%$ for each. For NLT events, it was 26 and $17 \%$, respectively.

The highest coverage of LT emergencies was for events in stratum 4 with $42 \%$ and for NLT events was in stratum 5 with $62 \%$. Comparing years of study in coverages of events by actual ESF in 2010 a coverage of LT emergencies in stratum 1 with an interval of time of 6 min was $40,20 \%$ in $2011,32 \%$ in $2013,49 \%$ in 2014 and $13 \%$ in 2015 . For NLT events, the coverage was $39 \%$ in $2010,53 \%$ in $2011,53 \%$ in $2013,49 \%$ in 2014 and $51 \%$ in 2015. This data show that NLT emergencies have a priority compared to LT urgencies. Ambulances were transporting NLT events more quickly than LT emergencies but this should be the opposite as LT is more urgent than NLT. 

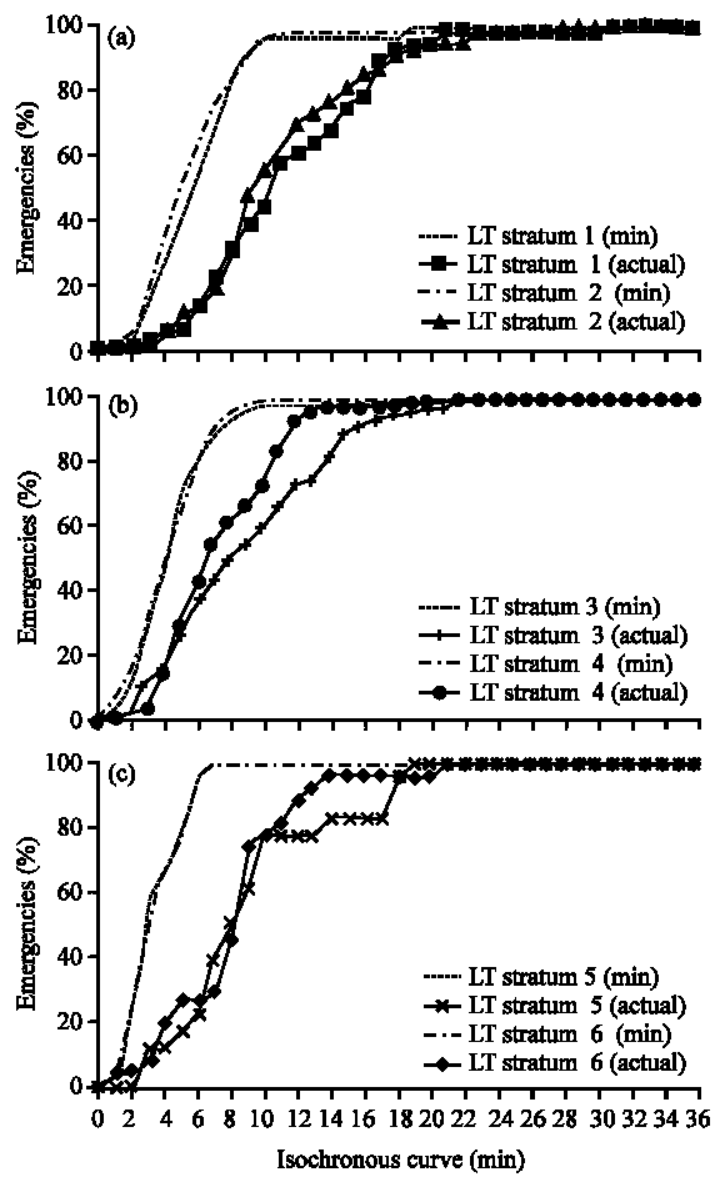

Fig. 9: Comparison of coverages between minimum response time and actual response time of LT emergencies by ESF and by stratum; a) 1 and 2; b) 3 and 4 and c) 5 and 6 researchers

Comparison of coverages between minimum travel time and actual travel time of LT emergencies by ESF: Like $\mathrm{AD}$ coverages, the LT emergencies in strata 5 and 6 had the highest gap of coverage (Fig. 9a-c). For instance with an interval of $6 \mathrm{~min}$ there was a difference of 74 and $70 \%$, respectively. For LT events in strata 1 and 2 , the gap was 52 and $53 \%$, respectively with an interval of time of $8 \mathrm{~min}$ (Fig. 9a-c). This means zones with a higher density of amenities and services (AD and ESF) generate greater loss of time due to poor execution of logistics.

In a comparison of gaps of coverage between years of study in LT emergencies in stratum 1 with $8 \mathrm{~min}$ of transport time, 2010 had the largest difference of coverage with $62 \%$ while in 2011 it was $31 \%$, in 2013 was $48 \%$, in 2014 was $46 \%$ and in 2015 was $53 \%$. For LT events in stratum 5 with $6 \mathrm{~min}$ of transport time, there was a difference of $35 \%$ in $2010,42 \%$ in $2011,61 \%$ in 2013 ,
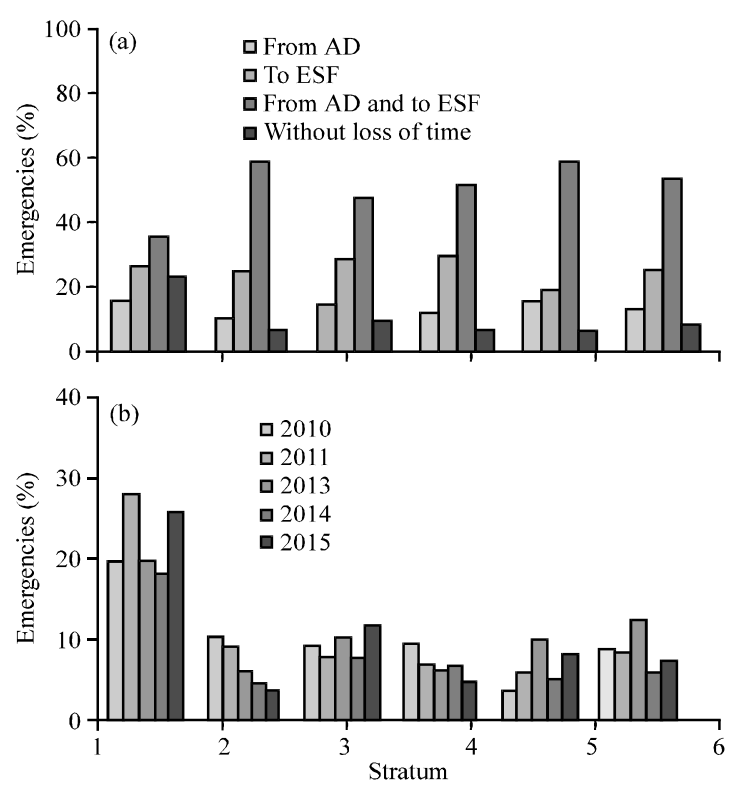

Fig. 10: Percentage of emergencies whit loss of time; a) By journey and stratum and b) By stratum and year researchers

$57 \%$ in 2014 and $74 \%$ in 2015. For ESF, the gap of coverage has been increasing in low income zones. In high income zones, there was decreasing with respect to $\mathrm{AD}$. Hence, there are two huge issues; first there is no policy in logistic of attention and second there is no policy in urban planning to generate an optimal coverage of both LT and NLT emergencies.

Loss of time: Knowing that the gap in coverage is considerable in each zone of the city, it is important to highlight that emergencies in stratum 1 had the highest percentage of events which did not lose time with $23 \%$ (Fig. 10a, b). Other strata just had approximately $8 \%$ of the events. Also, the highest $\%$ of emergencies lost time in both journeys from $\mathrm{AD}$ to event and from emergency to ESF in each stratum (as shown in Fig. 10a, b). A small fraction of events lost time only in the journey from $\mathrm{AD}$ to the event. Emergencies lost more time in journey from emergency to ESF due to the city having more ESF than $\mathrm{AD}$. This means that more amenities generate a higher probability of lost time.

The emergencies in stratum 3 had the greatest loss of time (sum of loss of time of each emergency) because these zones are where most emergencies took place and the largest population resides. As shown in Fig. 10b, the change between years was not relevant but emergencies in stratum 3 had an increasing tendency while other strata were constant or even decreasing. This correlation 
between population and loss of time was repeated in the rest of strata with an exception in stratum 4. High income zones had the lowest loss of time but these were the zones with the highest gap of coverage. Emergencies in strata 5 and 6 lost little time but these events did not go or were not attended by the nearest services (AD and $\mathrm{ESF}$ ). This supports the hypothesis that in zones with a high density of amenities, there is a higher probability of loss of time.

This research explored emergency medical services in Manizales, Colombia, highlighting that there is no clear regulation for optimal coverage for either $\mathrm{AD}$ or $\mathrm{ESF}$ and it is necessary to overcome the social gap and health inequalities. However, it is imperative to improve urban planning and management in logistics regarding emergencies, especially, if we desire a fair society with heathy lives. This process must start with children (Marmot and Bell, 2012) to overcome the terrible circumstances described in Guinea-Bissau where a study, conducted during the 1990's, evidenced that 20 of 125 ill children died on the way to hospital or waiting in the outpatient clinic (Sodemann et al., 1997). Hence, the government's and private sector's interest in health services should take into account low income zones, above profit.

The principal factor of social and health inequalities in access to Emergency medical Services (ESF and $A D$ ) is the lack of resources in peripheral and low income sectors. However, there are other factors that contribute to inequalities such as steep slope in developed road infrastructure. $\mathrm{ESF}$ or $\mathrm{AD}$ in some zones is a big challenge and those sectors are where poor people live. Hence, in this case, it is necessary to relocate these people in zones with low natural risk and land with excellent specifications to develop good amenities and services.

According to the results, low income zones had the worst coverage of emergencies in all cases with nearest and registered facilities. High income zones had the best coverage. This proves the social and health inequalities in access to emergency medical services, underlining that only $22 \%$ of emergencies fell within the optimal maximum response time ( $\mathrm{AD}$-event) and $38 \%$ of emergencies were within the optimal maximum transport time (event-ESF), considering actual conditions. In comparison to Mecklenburg, a county of 620,000 inhabitants located in North Carolina, $90 \%$ of LT emergencies were attended within $10 \mathrm{~min}$ and $59 \mathrm{sec}$ or less of response time (Blackwell and Kaufman, 2002). In Manizales, 90\% of LT events were attended within $14 \mathrm{~min}$ and $25 \mathrm{sec}$ or less of response time.

In the zone with the most emergencies, $91 \%$ of events lost time at least on one journey. In the majority of neighbourhoods, this pattern emerged, indicating a problem in paying attention to logistics. Comparisons between coverage with nearest amenities and with actual services demonstrated that most emergencies in high income zones lost time given that the event was not attended to by the nearest services. Also, zones with a high density of facilities had a higher probability of loss of time but if attention to logistics was better, this would not happen.

Most emergencies lost time in both journeys ( $\mathrm{AD}$ to events and events to ESF). In a comparison between two trips, emergencies lost time more frequently between event and ESF which could be happening due to the fact that some ESF are paying drivers of ambulances to transport the patient and these vehicles are not going to the nearest ESF. However, the ambulances could be going to another ESF in search for a better hospital which fulfils specific needs that the patient may require.

\section{CONCLUSION}

Between the coverage of LT and NLT emergencies, there was no difference in response time but according to transport time the NLT emergencies were covered more quickly than $\mathrm{LT}$ events. This could be the case for several reasons. First, a LT emergency sometimes requires special attention, meaning the ambulance seeks an ESF with human and equipment resources that the patient requires. Second, some ESF have been paying the paramedics or driver of ambulance to transport the patient to their ESF; this is an enormous issue in the health system.

Average passenger-car speed, used to measure travel time was taken to all types of vehicles (car, motorcycle and taxi) and this study could change significantly by including the actual speed of the ambulances, given that these vehicles drive more quickly than others. Hence, the coverages would be broader. Also, the characteristics included in the data base to determine the triage for some events did not specify vital signs which are indispensable to categorise the event. Moreover, some emergencies could be triage 4 and not triage 3 but there was enough information in the case of triage 1 and 2 . Furthermore, the capacity of the $\mathrm{AD}$ (number of ambulances) and beds available in each ESF were not taken into account to explain the reason why the emergency was not attended by nearest facility ( $\mathrm{AD}$ or ESF).

\section{RECOMMENDATIONS}

Future research should consider factors that produce loss of time, finding structural issues such as weak health system or even instances of misbehaving among the 
operators of the emergency medical services or ambulances. Also, taking into account the capacity of both $\mathrm{AD}$ and ESF could considerably change the results which is a main factor in the decision of $\mathrm{AD}$ and ESF that attend the emergency. Moreover, it would be interesting to look for inequalities in access to emergency medical services in terms of the type of patient (subsidised or: patient who does not pay for health insurance, contributor: patient who pays for health insurance or health insurance paid by vehicles in case of road accidents). According to the government of Colombia, the country has to improve prehospital and hospital attention to decrease deaths caused by road traffic collisions which is one of five pillars in the National Plan for Road Safety (Anonymous, 2016a, b). Hence, the methodology proposes by this study could be the first step to find zones where there is a higher need for amenities and services to advance emergency medical services.

\section{ACKNOWLEDGEMENTS}

The development of this research was possible thanks to the support of Engineering and Architecture Faculty of the National University of Colombia in Manizales who supported the execution thereof by Call 2013-2015, research code 28588. The researchers, especially, thank the Fire Brigade of Manizales, Colombia. Development Planning Unit of University College of London and Research group in sustainable mobility.

\section{REFERENCES}

Anonymous, 2011. [Mobility plan of the city of Manizales 2010-2040]. National university of Colombia, Manizales, Colombia. (In Spanish)

Anonymous, 2016a. National plan for road safety, colombia 2011-2021. Ministry of Transportation, Bogota, Colombia.

Anonymous, 2016b. [Municipal development plan 2016-2019]. Alcaldía de Manizales, Manizales, Colombia. (In Spanish)

Arreola-Risa, C., C.N. Mock, L. Lojero-Wheatly, O.D.L. Cruz and C. Garcia et al., 2000. Low-cost improvements in prehospital trauma care in a Latin American city. J. Trauma Acute Care Surg., 48: 119-124.

Bissonnette, L., K. Wilson, S. Bell and T.I. Shah, 2012. Neighbourhoods and potential access to health care: The role of spatial and aspatial factors. Health Place, 18: $841-853$.
Blackwell, T.H. and J.S. Kaufman, 2002. Response time effectiveness: Comparison of response time and survival in an urban emergency medical services system. Acad. Emergency Med., 9: 288-295.

Blanford, J.I., S. Kumar, W. Luo and A.M. MacEachren, 2012. It's a long, long walk: Accessibility to hospitals, maternity and integrated health centers in Niger. Intl. J. Health Geog., 11: $1-15$.

Chardon, A.C., 2008. [Resettlement and habitat in urban areas a reflection in Manizales (In Spanish)]. Cuad. Vivienda Urban, 1: 226-247.

Church, A., M. Frost and K. Sullivan, 2000. Transport and social exclusion in London. Transp. Policy, 7: 195-205.

Cromley, E.K. and S.L. McLafferty, 2011. GIS and Public Health. 2nd Edn., Guilford Press, New York, USA., ISBN: 978-1-60918-750-7, Pages: 504.

Geurs, K.T. and B.V. Wee, 2004. Accessibility evaluation of land-use and transport strategies: Review and research directions. J. Transp. Geog., 12: 127-140.

Geurs, K.T., 2001. Accessibility Measure: Review and Applications; Evaluation of Accessibility Impacts on Land-use Transport Scenarios and Related Social and Economic Impacts. Rijksinstituut voor Volksgezondheid en Milieu, Bilthoven, Netherlands, Pages: 265.

Graham, S. and S. Marvin, 2001. Splintering Urbanism: Networked Infrastructures, Technological Mobilities and the Urban Condition. Routledge, London, England, UK., Pages: 481.

Hawthorne, T.L. and M.P. Kwan, 2012. Using GIS and perceived distance to understand the unequal geographies of healthcare in lower-income urban neighbourhoods. Geog. J., 178: 18-30.

Hernandez, D.O. and H. Titheridge, 2016. Mobilities of the periphery: Informality, access and social exclusion in the urban fringe in Colombia. J. Transp. Geogr., 55: 152-164.

Higgs, G., 2004. A literature review of the use of GIS-based measures of access to health care services. Health Serv. Outcomes Res. Method., 5: 119-139.

Higgs, G., 2009. The role of GIS for health utilization studies: Literature review. Health Serv. Outcomes Res. Method., 9: 84-99.

Indriasari, V., A.R. Mahmud, N. Ahmad and A.R.M. Shariff, 2010. Maximal service area problem for optimal siting of emergency facilities. Intl. J. Geog. Inf. Sci., 24: 213-230. 
Li, J. and A.D. Heap, 2011. A review of comparative studies of spatial interpolation methods in environmental sciences: Performance and impact factors. Ecol. Inf., 6: 228-241.

Lucas, K., 2011. Making the connections between transport disadvantage and the social exclusion of low income populations in the Tshwane region of South Africa. J. Transp. Geogr., 19: 1320-1334.

Marmot, M. and R. Bell, 2012. Fair society, healthy lives. Publ. Health, 126: S4-S10.

Marmot, M., 2007. Achieving health equity: From root causes to fair outcomes. Lancet, 370: 1153-1163.

Matheron, G., 1963. Principles of geostatistics. Economic Geol., 58: 1246-1266.

McGrail, M.R. and J.S. Humphreys, 2014. Measuring spatial accessibility to primary health care services: Utilising dynamic catchment sizes. Appl. Geogr., 54: 182-188.

Munoz, U.H. and C. Kallestal, 2012. Geographical accessibility and spatial coverage modeling of the primary health care network in the Western Province of Rwanda. Intl. J. Health Geog., 11: 1-11.

Neutens, T., 2015. Accessibility, equity and health care: Review and research directions for transport geographers. J. Transp. Geogr., 43: 14-27.

Ohnmacht, T., H. Maksim and M. Bergman, 2009. Mobilities and Inequality-Making Connections. In: Mobilities and Inequality, Ohnmacht, T., H. Maksim and M. Bergman (Eds.). Ashgate Publisher, Farnham, England, pp: 7-26.
Pickett, K.E. and R.G. Wilkinson, 2015. Income inequality and health: A causal review. Soc. Sci. Med., 128: 316-326.

Pons, P.T., J.S. Haukoos, W. Bludworth, T. Cribley and K.A. Pons et al., 2005. Paramedic response time: Does it affect patient survival?. Acad. Emergency Med., 12: 594-600.

Razzak, J.A. and A.L. Kellermann, 2002. Emergency medical care in developing countries: Is it worthwhile?. Bull. World Health Organiz., 80: 900-905.

Sasaki, S., A.J. Comber, H. Suzuki and C. Brunsdon, 2010. Using genetic algorithms to optimise current and future health planning-the example of ambulance locations. Intl. J. Health Geogr., 9: 4-14.

Schmid, T., O. Kanenda, I. Ahluwalia and M. Kouletio, 2001. Transportation for maternal emergencies in Tanzania: Empowering communities through participatory problem solving. Am. J. Publ. Health, 91: 1589-1590.

Sheller, M. and J. Urry, 2006. The new mobilities paradigm. Environ. Plann. A., 38: 207-226.

Sodemann, M., M.S. Jakobsen, K. Molbak, I.C. Jr. Alvarenga and P. Aaby, 1997. High mortality despite good care-seeking behaviour: A community study of childhood deaths in Guinea-Bissau. Bull. World Health Organization, 75: 205-212.

Wang, X. and K. Kockelman, 2009. Forecasting network data: Spatial interpolation of traffic counts from Texas data. Transp. Res. Rec. J. Board, 2105: 100-108. 